\title{
Transformações na Paisagem da região Norte Fluminense
}

As Ruínas da Usina de Cana de Açúcar e Álcool de Pureza em São Fidélis (RJ)

Landscape Transformations in Northern Rio de Janeiro State: The Ruins of the Sugarcane and Alcohol Mill in Pureza, São Fidélis (RJ)

Des changements dans le paysage de la région Nord d'État de Río de Janeiro : Les Ruines de l'Usine de Canne à Sucre et Alcool à Pureza en São Fidélis (RJ) Las Transformaciones en el Paisaje de la Región Norte del Estado de Río de Janeiro: Las Ruinas del Molino de Caña de Azúcar y Alcohol en Pureza, en São Fidélis (RJ)

Rodrigo Pereira Pinheiro da Silva e Elis de Araújo Miranda

\section{(2) OpenEdition Journals}

\section{Edição electrónica}

URL: https://journals.openedition.org/terrabrasilis/5586

DOI: $10.4000 /$ terrabrasilis. 5586

ISSN: 2316-7793

\section{Editora}

Rede Brasileira de História da Geografia e Geografia Histórica

\section{Refêrencia eletrónica}

Rodrigo Pereira Pinheiro da Silva e Elis de Araújo Miranda, «Transformações na Paisagem da região Norte Fluminense», Terra Brasilis [Online], 12 | 2019, posto online no dia 29 dezembro 2019, consultado o 05 dezembro 2022. URL: http://journals.openedition.org/terrabrasilis/5586 ; DOI: https://doi.org/ 10.4000/terrabrasilis.5586

Este documento foi criado de forma automática no dia 5 dezembro 2022.

All rights reserved 


\title{
Transformações na Paisagem da região Norte Fluminense
}

\author{
As Ruínas da Usina de Cana de Açúcar e Álcool de Pureza em São Fidélis \\ (RJ) \\ Landscape Transformations in Northern Rio de Janeiro State: The Ruins of the \\ Sugarcane and Alcohol Mill in Pureza, São Fidélis (RJ) \\ Des changements dans le paysage de la région Nord d'État de Río de Janeiro: Les \\ Ruines de l'Usine de Canne à Sucre et Alcool à Pureza en São Fidélis (RJ) \\ Las Transformaciones en el Paisaje de la Región Norte del Estado de Río de \\ Janeiro: Las Ruinas del Molino de Caña de Azúcar y Alcohol en Pureza, en São \\ Fidélis (RJ)
}

Rodrigo Pereira Pinheiro da Silva e Elis de Araújo Miranda

\section{NOTA DO AUTOR}

Este trabalho é parte integrante do Projeto de Pesquisa Ruínas do Açúcar, coordenado pelos professores Marcelo Werner da Silva e Elis de Araújo Miranda. Contou com o financiamento CNPq por meio de Bolsa de Iniciação Científica (PIBIC 2018-2019) e da CAPES por meio do Programa de Apoio à Pós-Graduação (PROAP).

\section{Introdução}

1 A Usina Pureza, fundada em 1885 a partir da política Imperial de construção dos Engenhos Centrais, foi a maior expressão do município de São Fidélis-RJ na economia sucroalcooleira, que teve pujança na Região Norte Fluminense ao longo dos séculos XVIII e XIX, mas que a partir das primeiras décadas do século XX encontrou uma série de dificuldades, entrando em franca decadência culminante no atual estado de desmonte das estruturas produtivas. Diante desse panorama, a Usina Pureza teve seu 
funcionamento cada vez mais inviabilizado pelas circunstâncias adversas da desarticulação produtiva do setor e do direcionamento da economia regional à atividade petrolífera, até que foram oficialmente encerradas as atividades da indústria no ano de 2009.

2 Tendo passado uma década desta data e não havendo perspectivas futuras, a estrutura da indústria e seus objetos relativos ainda remanescentes apresentam hoje diferentes graus de conservação/degradação, resultando numa paisagem composta por múltiplas formas-ruínas, aparentemente esvaziadas de funções, porém dotadas de fortes simbolismos. Estações e linhas de trem, vilas operárias, praças, templos religiosos, pontes e rodovias são alguns dos objetos geográficos advindos da espacialização do Engenho Central, exercendo relações em maior ou menor grau com essa unidade industrial, que fora o núcleo da organização local do "mundo do açúcar" em São Fidélis.

Busca-se fazer uma leitura da atual paisagem da Usina Pureza a partir de duas perspectivas: i) as transformações e permanências materiais dos objetos geográficos após o encerramento das atividades produtivas; ii) a historicidade e o simbolismo das formas relacionadas ao sistema produtivo sucroalcooleiro. Importa ressaltar que o registro fotográfico foi feito pelos autores durante a realização de trabalhos de campo na área da Usina Pureza e em outras usinas do Norte Fluminense que também se encontram desativadas. reconhecendo, dessa maneira, a existência de um sistema produtivo interligado que marcou um período histórico da economia do Brasil.

4 Assim, espera-se compreender como se deu a composição espacial da usina e das áreas ao seu entorno a partir dos processos históricos de formação socioespacial, considerando a dialética entre forma, função, estrutura e processo que caracteriza o espaço geográfico (Santos, 2014a; 2014b), atentando-se também às questões simbólicas inerentes à subjetividade das formas, uma vez que entende-se a paisagem enquanto expressão cultural, e sendo assim, dotada de intencionalidades e de uma carga ideológica que busca se naturalizar a partir dela.

\section{As Paisagens do Norte Fluminense Sucroalcooleiro}

5 As transformações nas/das paisagens do Norte Fluminense estão diretamente associadas à trajetória da economia sucroalcooleira, que fora historicamente a principal atividade produtiva desta região. Iniciada ainda no século XVII com o estabelecimento das primeiras lavouras de cana-de-açúcar, a produção do açúcar experienciou grande êxito durante o século XIX e nas duas primeiras décadas do século XX sendo esse o período de maior dinamismo das transformações das paisagens, tendo sido realizadas a construção de engenhos e usinas, a instalação de uma malha ferroviária, a canalização de rios e uma série de outras modificações (Lamego, 2007; Silva, 2019).

Diante da acumulação de capitais, as elites açucareiras se estabeleceram nesse período como os principais agentes modeladores do espaço regional, o que se estendeu até a eclosão da crise de superabastecimento de 1929 causada pela baixa dos mercados internacionais. A partir daí, houve uma série de transformações na agroindústria brasileira, que passara a ser regulada pelo Governo Federal por meio de órgãos como o Instituto do Açúcar e do Álcool (IAA) que dentre outras funções reguladoras, exercia o controle sobre as cotas de produção das usinas e engenhos, sendo fundamental para continuidade do setor num primeiro momento, mas, ao passar dos anos, acabou por 
transformar o perfil dos empresários usineiros, outrora empreendedores, numa classe imobilizada e dependente do Estado (Gantos et al., 2006; Silva, 2019; Smiderle, 2010).

7 O quadro de declínio começa a ser mais bem evidenciado a partir da década de 50 do século XX, quando São Paulo assumiu o protagonismo desse setor produtivo no território nacional, sendo ainda mais agravado pela concorrência da atividade petrolífera, iniciada no Norte do Estado do Rio de Janeiro a partir de 1970. O encerramento das atividades produtivas da quase totalidade das unidades produtivas $\mathrm{e}$ a transmutação de parte dessas estruturas em ruínas marca a atual configuração dessas paisagens nos dias de hoje, bem como a presença espaços vazios ou estacionamentos que indicam a demolição de prédios históricos e grandes áreas de pastos que um dia foram áreas de plantações de cana-de-açúcar (Smiderle, 2010; Silva, 2019; Piquet, 2003).

\section{Trajetória da Usina Pureza no Norte Fluminense Sucroalcooleiro}

8 A trajetória do Engenho Central de Pureza se inicia antes mesmo de sua construção, com a ocupação da área hoje compreendida pelo município de São Fidélis, que fora até 1870 parte de Campos dos Goytacazes. Os colonos que lá se localizaram iniciaram os primeiros cultivos de cana e demais gêneros agrícolas que vieram a ser o principal motor do desenvolvimento local.

Pouco após sua emancipação, a política do Governo Imperial de construção dos Engenhos Centrais entrou em vigor, tendo como marco a fundação do Engenho Central de Quissamã em 1877, primeira indústria desse modelo em toda América Latina. A partir daí foi estabelecida uma série de empreendimentos desse gênero pelo Norte Fluminense, até que em 1884 foi fundado em São Fidélis o Engenho Central de Pureza, nas terras da fazenda Pureza, propriedade de colonos franceses que se estabeleceram no distrito conhecido incialmente como Dois Rios, hoje denominado Colônia (Silva, 2019).

10 Há uma questão toponímica entre o nome da usina e o nome do distrito vizinho, também denominado Pureza. Isso se deu por conta da influência da própria usina, uma vez que seu funcionamento se integrava à rede ferroviária que veio a ser instalada no antigo distrito de Timbó. Era comum em toda a região que as estações de trem ganharem a alcunha dos engenhos ou usinas que se localizavam próximos, não sendo diferente neste caso. Assim, a estação passou a ser denominada Estação de Pureza e a vila que se desenvolvera ao seu entorno foi cunhada como Vila de Pureza. Por fim, na década de 30 do século XX, o distrito de Timbó, exercendo maior centralidade, também veio a incorporar o nome, passando a se chamar Distrito de Pureza.

11 Percebe-se a grande influência dessa unidade produtiva em todo território de São Fidélis e principalmente nesses dois distritos - Colônia e Pureza. Além disso, foi um importante agente da integração regional que se deu principalmente a partir da Estrada de Ferro Leopoldina, responsável por integrar os lugares produtores do açúcar no Norte do Estado do Rio de Janeiro, compondo um sistema produtivo regional e possibilitando o escoamento da produção de forma mais fluida em direção à capital, onde o açúcar era negociado e direcionado aos mercados estrangeiros.

12 A estrada férrea que veio a passar por São Fidélis, hoje desativada, tinha seu ponto de partida no município de Miracema, localizado hoje na região Noroeste do estado do Rio 
de Janeiro, e seguia com destino a Campos dos Goytacazes. Seu traçado era paralelo ao Rio Paraíba do Sul. Chegando ao município de Campos, as locomotivas se direcionavam da ferrovia longitudinal que ligava o Norte do estado à capital do Rio de Janeiro. 0 escoamento produtivo teve uma forma dendrítica obediente à hierarquia de centralidade seguinte: Pureza (Centralidade local) - São Fidélis (Sub-centralidade regional) - Campos (Centralidade regional) - Rio de Janeiro (Centralidade nacional e parte integrante do sistema mundo).

O mapa seguinte mostra a localização da Usina Pureza no município de São Fidélis. Pode-se observar sua posição relativa ao Rio Paraíba do Sul, à desativada Estrada de Ferro Leopoldina e às rodovias ao entorno, bem como sua localização dentro da Região Norte Fluminense. Além disso, é importante notar a divisão político-administrativa interna do município, principalmente os distritos destacados em tom mais escuro, que foram imediatamente influenciados por ela: Colônia e Pureza, com destaque para a localização da Usina no distrito de Colônia.

Figura 1. Localização da Usina Pureza no município de São Fidélis, RJ

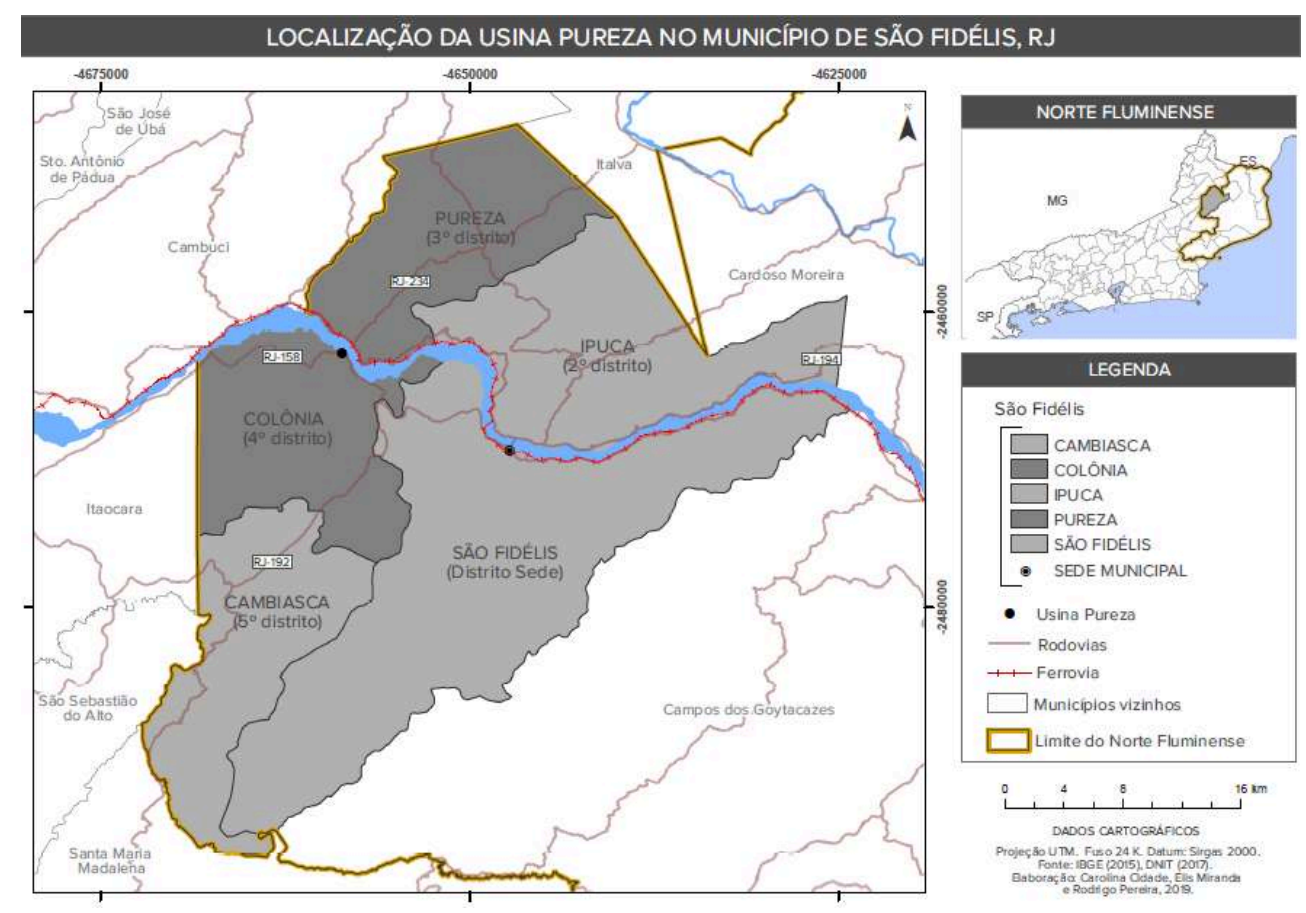

FONTE: Elaboração própria

Com o redirecionamento do país ao rodoviarismo a partir de meados do século $\mathrm{XX}$, os ramais ferroviários foram sendo desativados, o que causou impacto em todo o sistema de circulação da região. Houve prejuízos para a agroindústria do norte-noroestefluminense, assim como promoveu a diminuição do fluxo de pessoas no espaço regional. Em Pureza, isso constituiu-se em um problema, uma vez que as rodovias que lhe davam acesso eram poucas e encontravam-se em péssimas condições de conservação. Somavase a essa questão a dificuldade cada vez maior de se obter matéria-prima, que tornou custosa a operação da usina, ficando praticamente inviabilizado o funcionamento da usina em 2009, quando foram oficialmente encerradas as atividades produtivas da unidade. 


\section{Composição e Simbolismo da Paisagem da Usina Pureza}

15 Sendo o espaço formado por sistemas de objetos e sistemas de ações, reconhecemos a produção das formas como dotada de intencionalidades, significados, simbolismos e história. Como foram constituídas no bojo do sistema capitalista, as formas que compõem as paisagens devem ser entendidas a partir dos elementos representativos das distintas classes sociais envolvidas (Santos, 1996).

De modo consonante, geógrafos da escola de pensamento conhecida como Nova Geografia Cultural propuseram diferentes abordagens do fenômeno simbólico das paisagens e seu caráter ideológico. Para Denis Cosgrove $(2000 ; 2012)$, há uma relação intrínseca entre a paisagem e os símbolos que se dá pelo poder que o homem tem de intervir no espaço. Sendo a paisagem um meio de transmissão cultural, sua simbologia é carregada de códigos emitidos pelos grupos dominantes que assim impõe normas, padrões culturais e controle social sobre os demais grupos da sociedade. Sendo um através do qual um sistema sociocultural é experienciado, contestado e transmitido. A paisagem deve ser compreendida como resultante da forma como a sociedade a organiza e seu processo histórico.

17 A Mesorregião Norte Fluminense é caracterizada pela atuação de uma oligarquia do açúcar como principal agente modelador do espaço. A partir da acumulação de capital gerada no período áureo da economia sucroalcooleira, esses grupos transformaram as paisagens de acordo com suas visões de mundo, estabelecendo formas hegemônicas dotadas de um viés classista, que exprimem a contradição entre o discurso do progresso tecnológico industrial e a manutenção de estruturas socioeconômicas verticalizadas.

18 Analisaremos, então, a atual paisagem da Usina Pureza e das áreas ao seu entorno, identificando os principais objetos geográficos relacionados à produção do açúcar e reconhecendo os diferentes estados de conservação ou deterioração, as funções que cumprem hoje e os aspectos simbólicos que ainda carregam.

19 A seguinte imagem (Figura 2), encontrada na Monografia de São Fidélis realizada pelo IBGE, datada de 1975, retrata o conjunto de construções que compunham o Engenho Central de Pureza. 
Figura 2. Representação do Engenho Central de Pureza

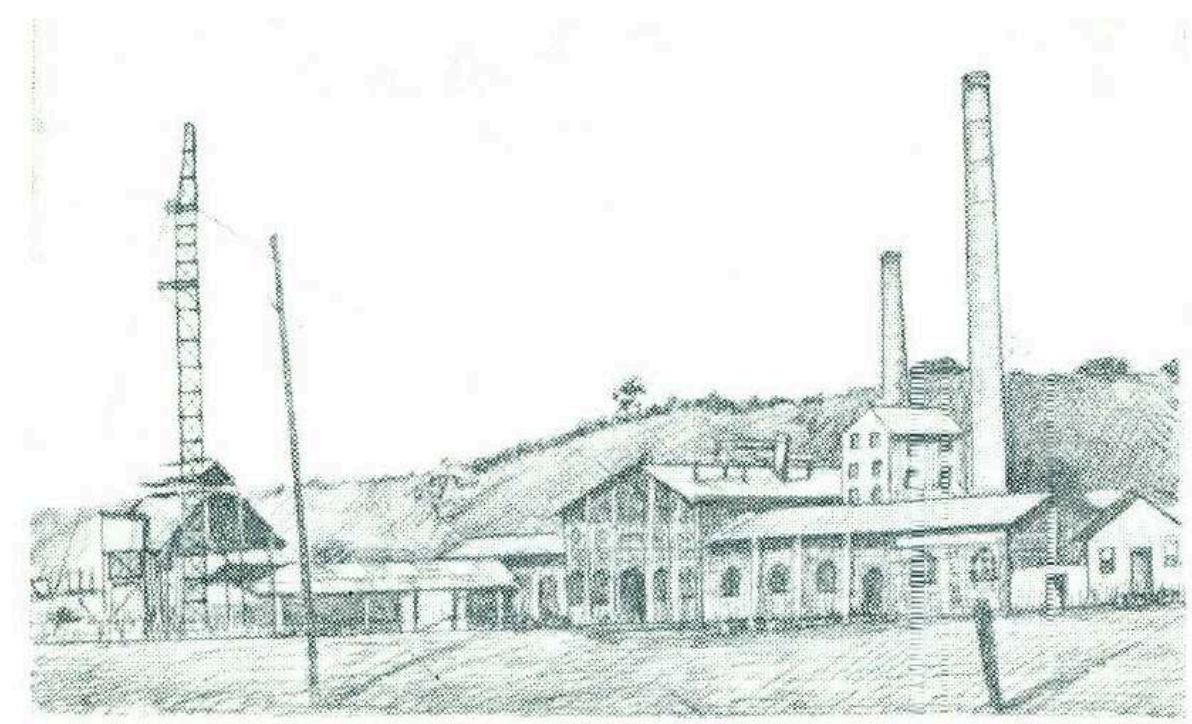

FONTE: IBGE (1975)

Chama atenção o prédio em forma de chalé, onde ficava localizado o escritório administrativo. Nota-se que é mais alta edificação, abaixo apenas das torres e chaminés. Essa disposição indica uma posição de controle dessa estrutura, onde a gerência se localizava sobre as instalações propriamente ditas, já que de lá poder-se-ia observar o funcionamento da indústria e a atividade dos trabalhadores de "chão de fábrica", dedicados ao trabalho operacional da usina.

21 A magnitude das Grandes Centrais não estava apenas associada à potencialidade na produção de açúcar, sobretudo, expressava o poder e a opulência dos agentes hegemônicos modeladores do espaço em questão. Conceição (2016), ao analisar o simbolismo das chaminés das usinas, relata que em toda região a concretude do poder expresso na paisagem era disseminada por meio das chaminés ou das torres dos engenhos centrais e usinas de cana-de-açúcar no período de bonança da economia sucroalcooleira. As chaminés das usinas fazem parte da paisagem da região Norte Fluminense até a atualidade como um símbolo da presença e permanência dos usineiros no comando das terras do campo e da cidade.

Na Figura 3 podemos observar a atual configuração da Usina Pureza e compará-la com a representação anterior. Nota-se que foram retiradas as antigas torres, substituídas por um modelo de menor porte (Figura 4), o que se deu por razões técnicas, quando as antigas chaminés se tornaram obsoletas. E mesmo em ruínas, o prédio do administrativo permanece como símbolo de poder. 
Figura 3: Panorama do Engenho Central de Pureza

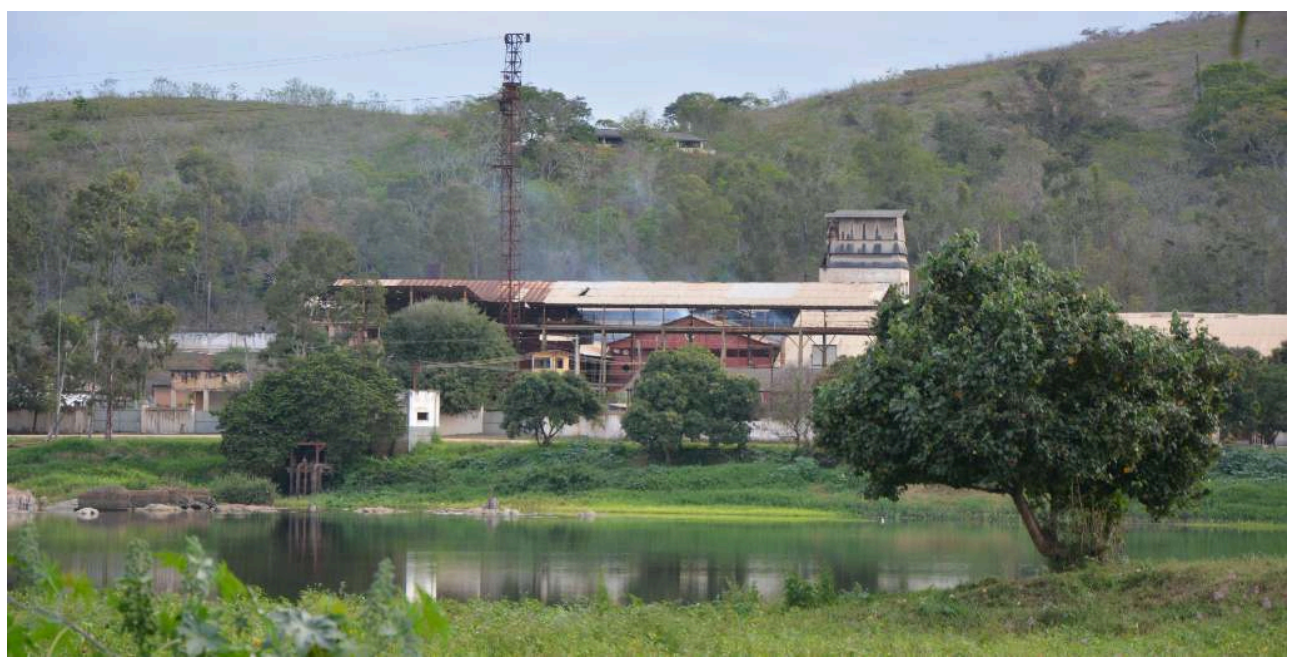

FonTE: Elis Miranda, 2018 (Acervo Fotográfico do LabCult)

Figura 4: Atuais chaminés da Usina Pureza

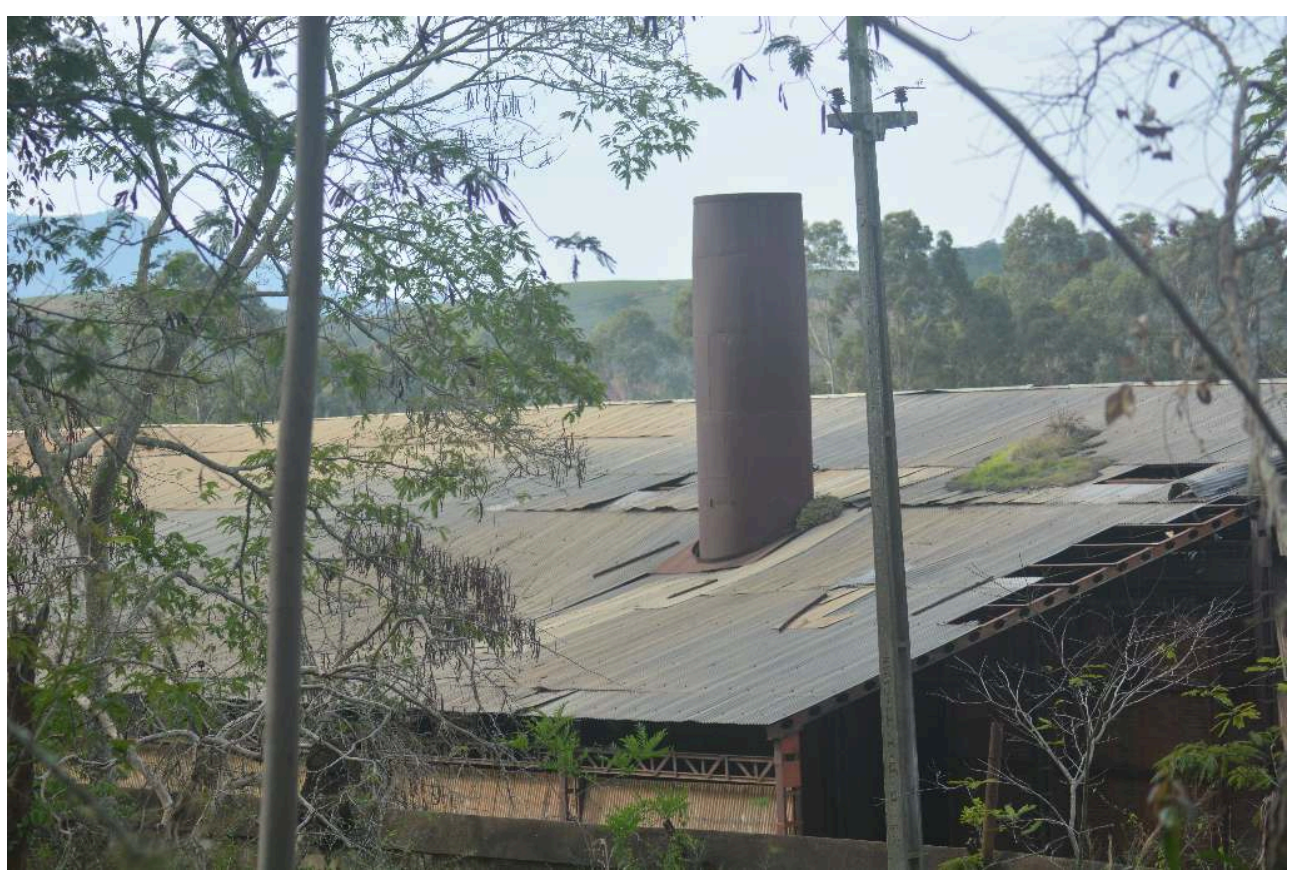

FonTE: Elis Miranda, 2018 (Acervo Fotográfico do LabCult)

23 Ao observar a fachada do Engenho Central na Figura 5 é interessante observar que foi preservado o escrito "Engenho Central da Puresa", nome original da indústria, que após as sucessivas administrações, foi alterado para "Usina Pureza" e "UPIC". A manutenção da grafia original acompanhada do ano de fundação são elementos que parecem evocar um certo tradicionalismo da indústria ou apelo à sua importância histórica. Como se a data de fundação retratasse o período em que o usineiro atua na e pela região, como uma representação de confiança e respeito. 
Figura 5: Parte frontal do Engenho Central

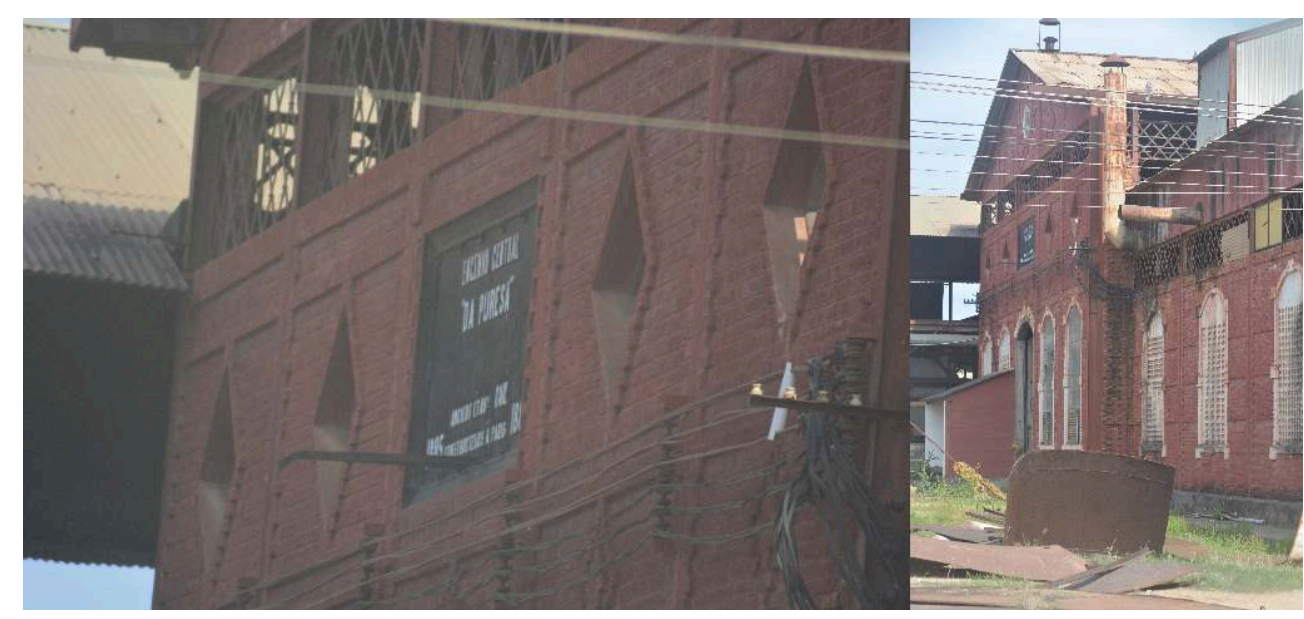

FONTE: Elis Miranda, 2018 (Acervo Fotográfico do LabCult)

24 Ainda sobre a Figura 5, a arquitetura dos edifícios também pode ser considerada uma expressão de poder das elites locais. Tendo sido desenhadas em Paris por um arquiteto francês, suas formas representam a marca do poderio dos colonos franceses nessas localidades (Silva, 2019). A chancela de que tudo que vinha da Europa significava ser de boa qualidade, além de representar status ao usineiro que mantinha relações comerciais em mercados estrangeiros.

A respeito da conservação das estruturas, importa observar os diferentes graus de degradação entre os distintos objetos. O pátio interno da Usina (Figuras 6 e 7), hoje, apresenta abandono e em estágio avançado de degradação, revelando a presença de formas-ruínas. Em oposição a este abandono da área produtiva, a vila dos antigos trabalhadores da usina encontra-se na área externa (Figura 8), em bom estado de conservação, sendo usada como moradia desses antigos trabalhadores, que ainda vivem saudosos dos tempos pretéritos. O prédio da usina, a vila dos trabalhadores, a igreja e a natureza que os emoldura compõem uma paisagem que nos faz imaginar a vida ativa que existiu outrora em São Fidélis, em oposição a esta imagem de abandono que se encontra atualmente. 
Figura 6. Pátio interno da Usina

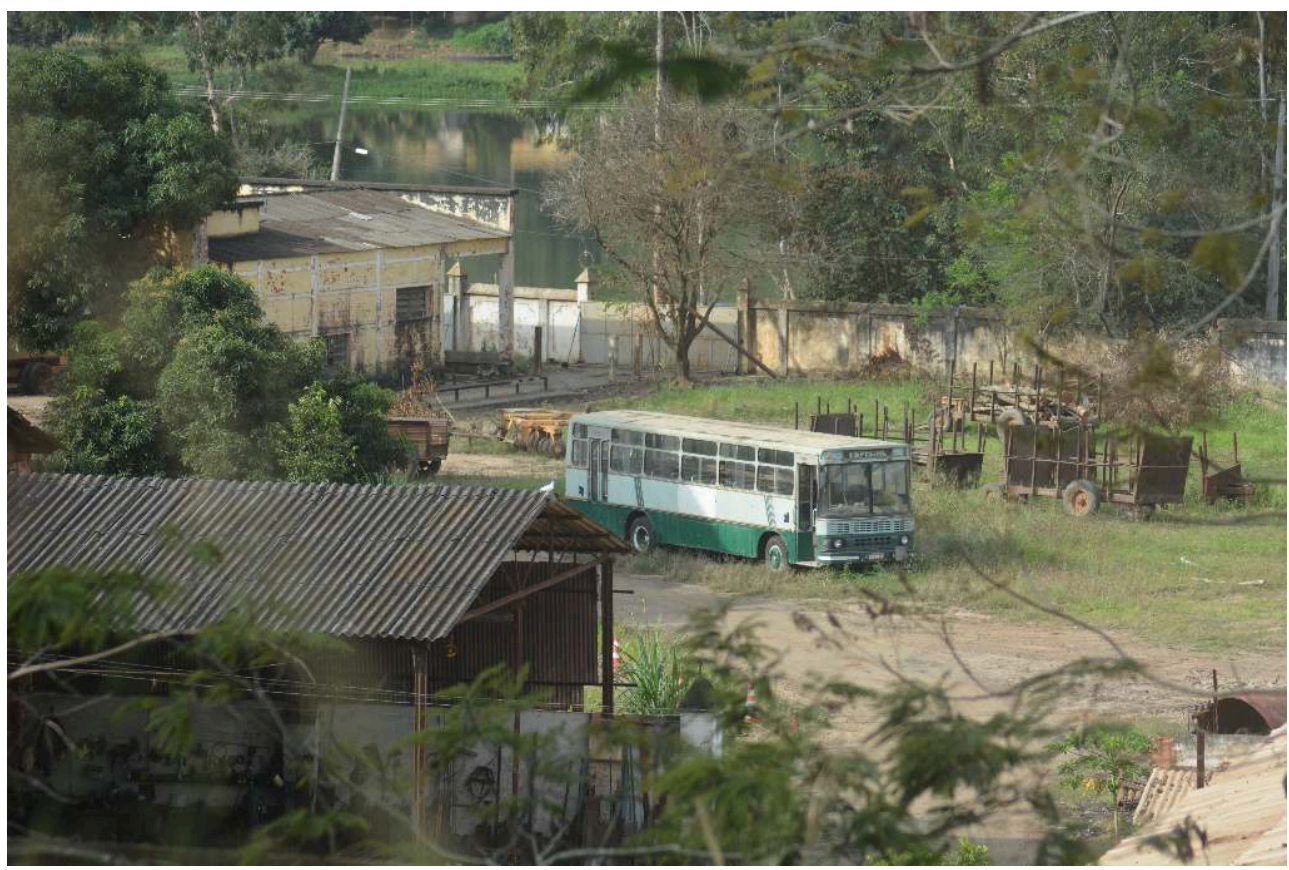

FonTE: Elis Miranda, 2018 (Acervo Fotográfico do LabCult)

Figura 7. Pátio interno da Usina e parte do galpão

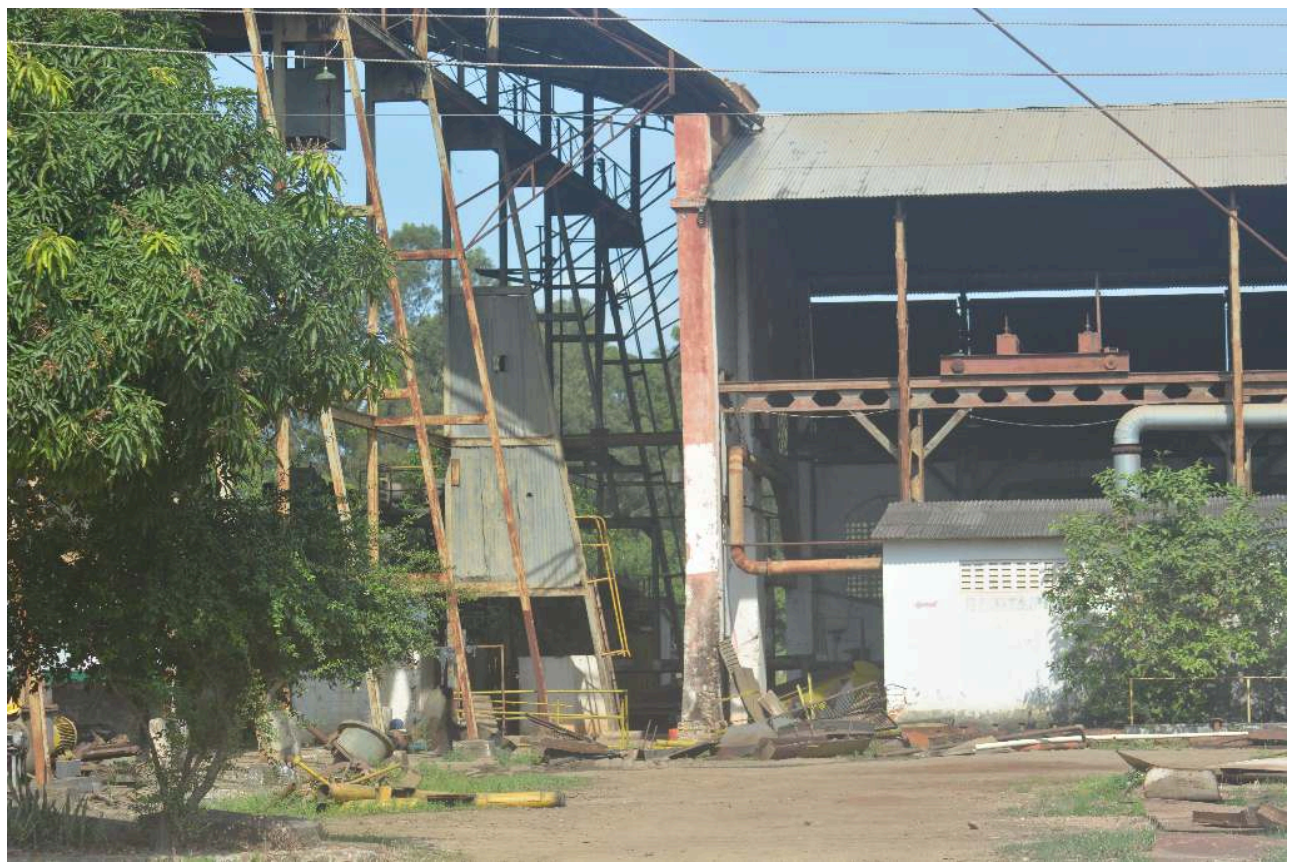

FONTE: Elis Miranda, 2018 (Acervo do LabCult) 
Figura 8. 0 padrão da Vila dos trabalhadores da Usina Pureza

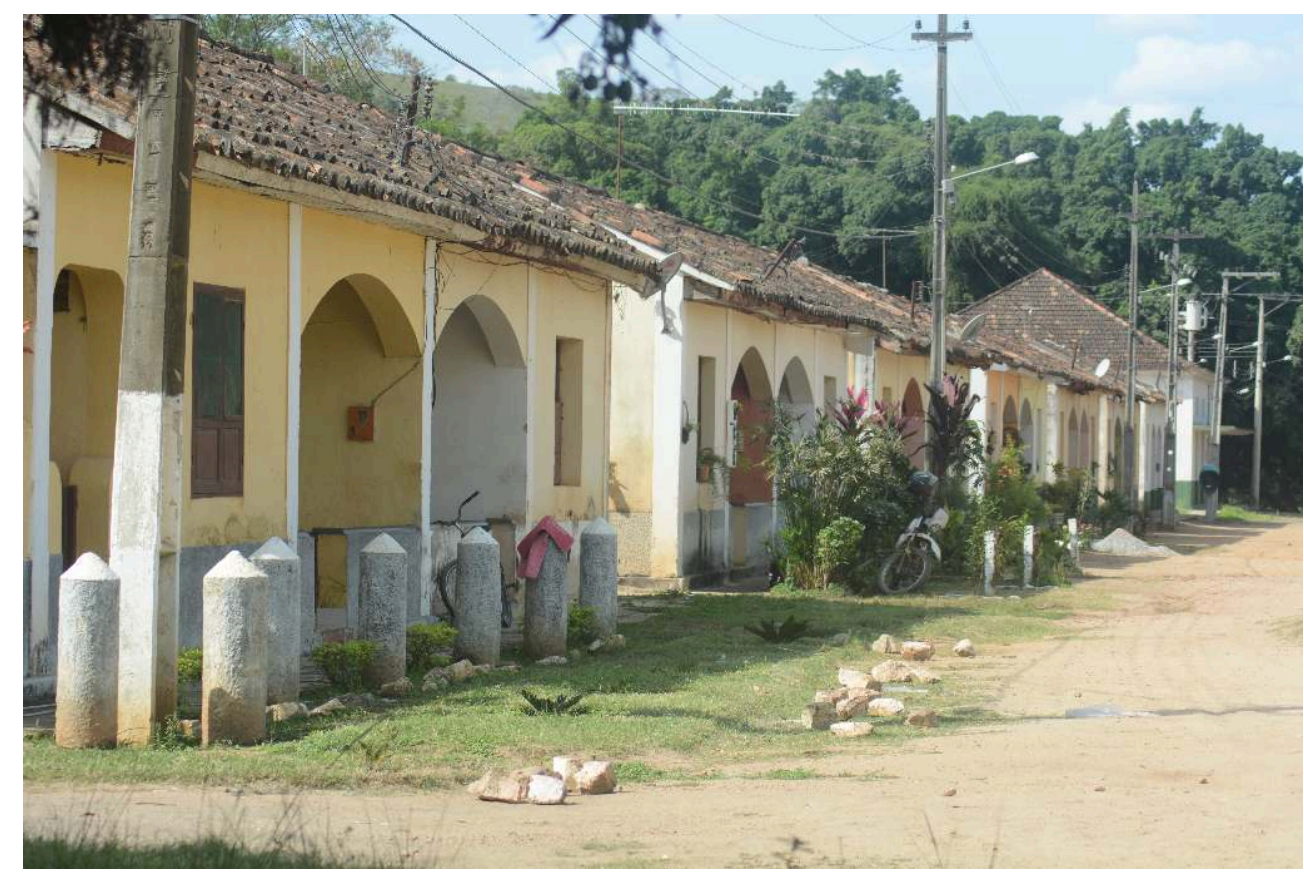

FonTE: Elis Miranda, 2018 (Acervo Fotográfico do LabCult)

A Vila dos trabalhadores da Usina Pureza é formada pelo conjunto de casas construídos ao entorno da usina. As construções padronizadas segundo uma ordem racionalista revelam a legitimação do controle que os usineiros exerciam sobre o proletariado, demonstram como os grupos do poder hegemônico empunham a ordem e o controle aos demais grupos, conforme mencionado por Cosgrove (2012).

O sistema produtivo das usinas demandava um contingente significativo de trabalhadores rurais. No entanto, não encontramos, na paisagem das usinas e no seu entorno imediato, referencias espaciais da presença desses trabalhadores, o que aponta para uma questão que deve ser levantada sobre a invisibilidade desse grupo social, os denominados "boias-frias".

Dentre as demais formas analisadas como objetos relativos à produção sucroalcooleira ainda remanescentes na paisagem, as habitações da vida operária são os que preservam as melhores condições materiais, exercendo ainda suas funções originais, mesmo após o encerramento das atividades na usina. Muitos dos antigos trabalhadores permaneceram nesses espaços, onde já haviam se estabilizado ao longo dos anos.

A preservação dessa materialidade pelos moradores da vila destoa das condições da própria fábrica, revelando de certa maneira o valor simbólico ainda resguardado sobre ela. Essa paisagem é remete as memórias dos trabalhadores que ali se estabeleceram e deram vida a esses espaços, a partir dos vínculos de convivência e das forças resistentes de contiguidade.

30 Um elemento dissonante na paisagem da Vila dos trabalhadores da Usina Pureza é a casa que hoje pertence ao administrador da usina (Figura 9), que em contextos pretéritos, fora destinado a moradia do chefe mecânico, um cargo de prestígio dentro do sistema sucroalcooleiro aos fins do século XIX e início do século XX. As diferenças significativas entre essas construções para as demais revelam a estratificação dos trabalhadores segundo um viés classista, em que os trabalhadores da lavoura 
representavam as classes mais baixas, seguidas pelos operários de "chão de fábrica" e em um grau acima estavam os cargos especializados de maior prestígio, como o do chefe mecânico e administrativos, referentes a gerência da empresa.

E onde morava o usineiro e sua família? Poderiam morar nas casas das fazendas ou nos palacetes na cidade de Campos dos Goytacazes, onde se concentravam os principais equipamentos de educação, cultura e lazer da elite canavieira.

Figura 9. Casa do administrador da Usina Pureza, antes casa do chefe mecânico

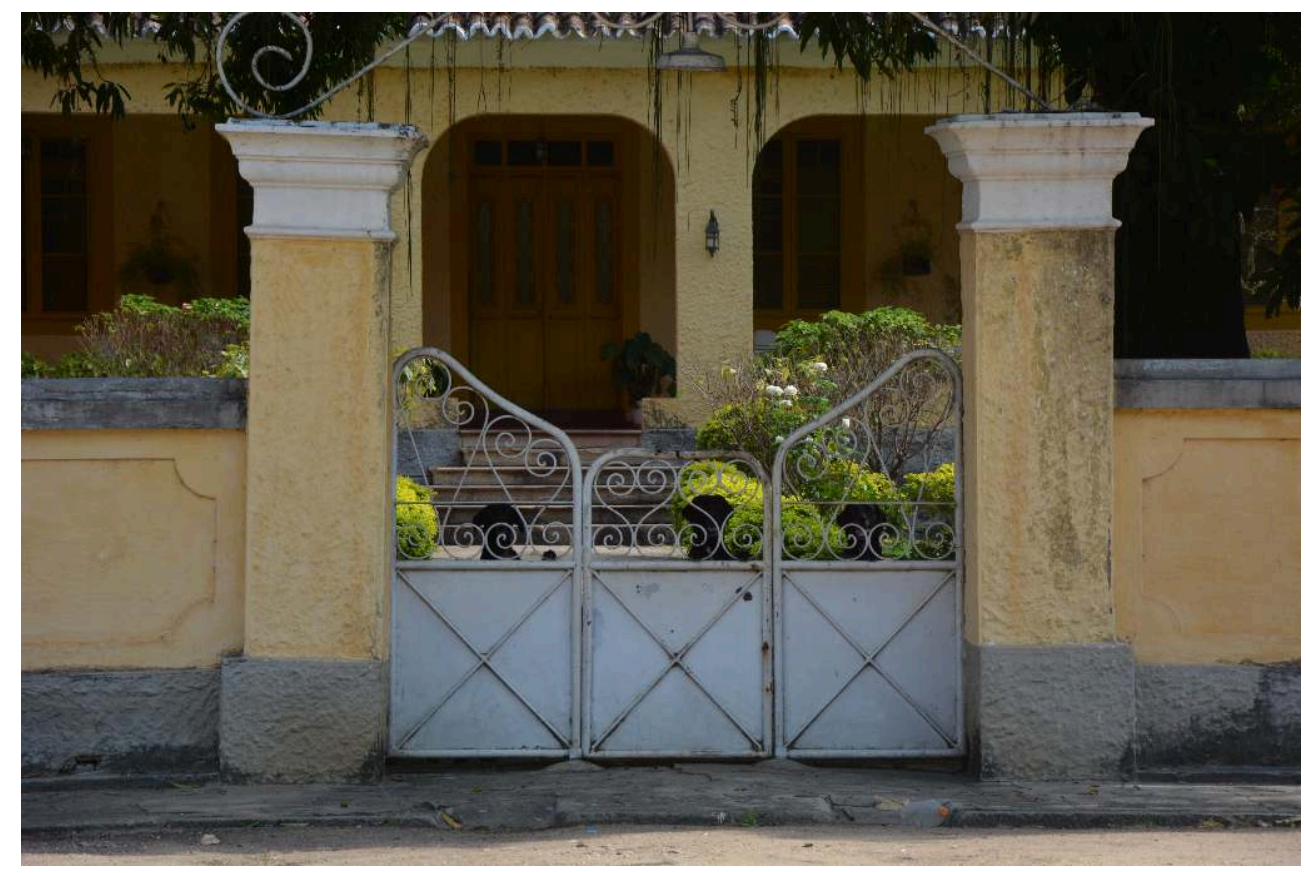

FONTE: Elis Miranda, 2018 (Acervo do LabCult)

A estação e a linha férrea (Figuras 10 e 11), que compõe ainda hoje a paisagem de Pureza são as estruturas que há mais tempo encontram-se fora de funcionamento, estando desativadas desde aproximadamente a década de 80 do século XX. Encontra-se, porém, preservado o substrato material da estação e das linhas férreas, ainda que desfuncionalizados por um longo período. 


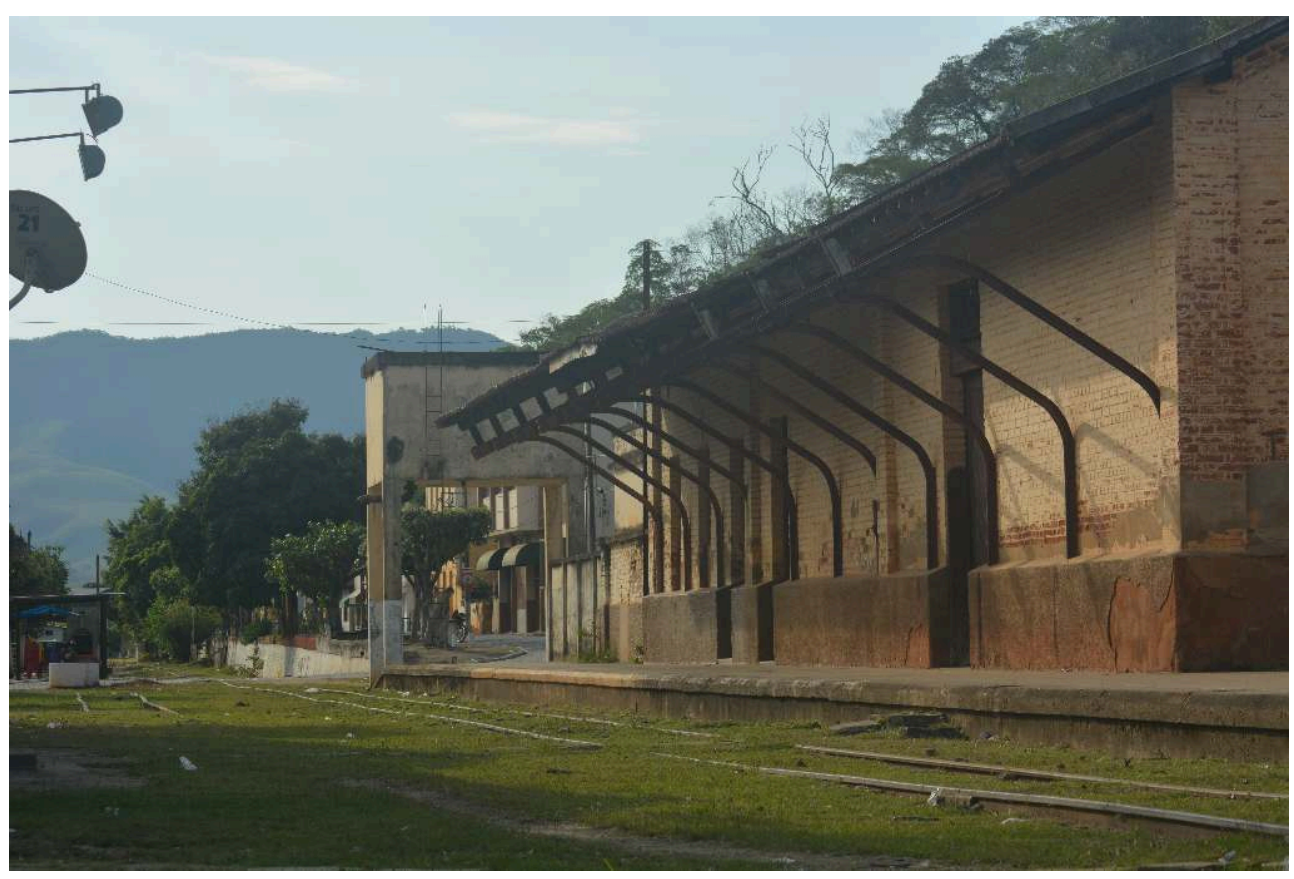

Fonte: Elis Miranda, 2018 (Acervo Fotográfico do LabCult)

Figura 11. Atual estado da Estação de Pureza

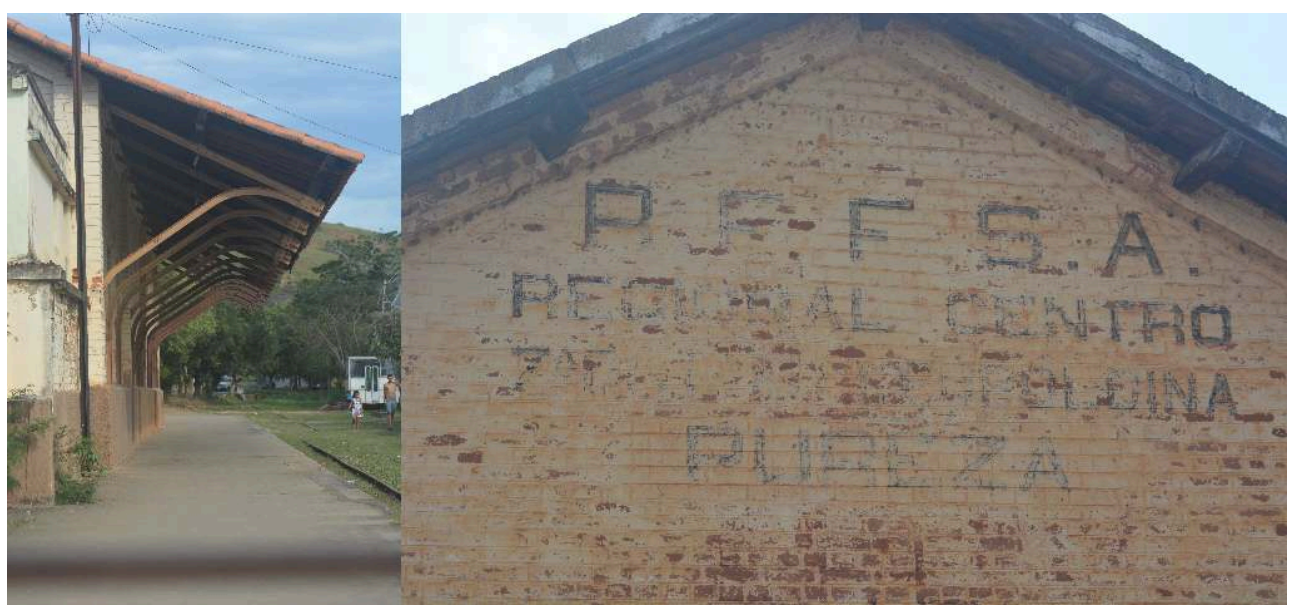

FONTE: Elis Miranda, 2018 (Acervo Fotográfico do LabCult)

Formas remanescentes do sistema ferroviário são encontradas em inúmeras cidades brasileiras e são tidas de maneira geral como elementos históricos, tendo sido refuncionalizadas, a exemplo das Estações da Luz e Júlio Prestes em São Paulo; do complexo ferroviário de Paranapiacaba, em São André; das Estações de Tiradentes e São João Del Rey em Minas Gerais. Os trilhos e estações de trem sempre estiveram bastante presentes no imaginário social, antes um símbolo de progresso e de modernização, hoje um símbolo de abandono e decadência ou nostalgia e memória.

Em Pureza, após se encerrar a atividade da ferrovia, o muro da linha férrea foi ressignificado como um painel onde são gravadas pinturas e poesias dos moradores de 
Pureza e das vilas ao entorno (figura 12). A poesia é uma expressão cultural em toda cidade de São Fidélis, reconhecida sob a alcunha de "Cidade-poema".

Figura 12. Linha férrea e seu muro, ressignificado pela população como um mural artístico

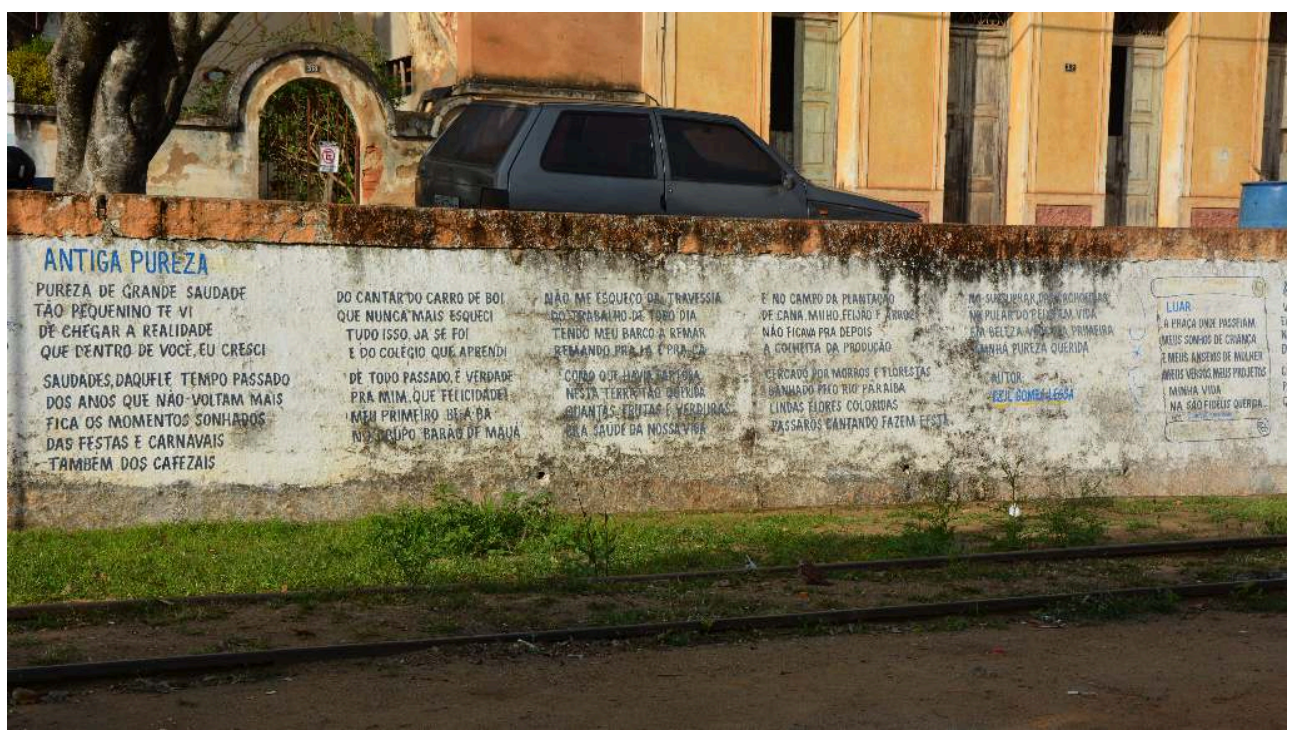

FONTE: Elis Miranda, 2018 (Acervo Fotográfico do LabCult)

\section{Considerações finais}

35 A manutenção dessas ruínas leva a pensar a partir de duas perspectivas: a) a primeira a respeito do reconhecimento da importância desses prédios para a história e a memória local e regional b) a falta de recursos financeiros para demolir aquela estrutura abandonada leva à manutenção dessas estruturas na paisagem.

Os diversos objetos analisados possuem distintas temporalidades e graus de conservação. As funções exercidas por cada forma perdem e ganham novos sentidos em diferentes contextos espaço-temporais (Santos, 1996; 2014a).

37 A ferrovia e a estação de trem são os elementos espaciais que há mais tempo encontram-se esvaziados de funções, entretanto, conservam um forte apelo histórico. A vila dos trabalhadores da usina conserva ainda seu padrão arquitetônico tradicional e cumpre ainda função de moradia, de lazer e cultura nos espaços comuns. Já o Engenho Central de Pureza propriamente dito apresenta-se como uma paisagem-ruína, esvaziada de sua função e carregada de significados.

38 As terras no entorno das usinas também nos chamaram atenção. A quem pertencem essas terras? Aparentemente não são terras produtivas. Quando as usinas foram vendidas, os usineiros venderam as terras do entorno ou apenas as fábricas já falidas, livrando as terras de possíveis contestações da justiça trabalhista ou de contestações de dívidas com o Estado?

39 As formas conservam simbolismos que representam o poder das elites do açúcar. A paisagem é repleta de uma carga ideológica e revela, a partir de sua leitura, a imposição de um padrão de classes espacialmente posto na monumentalidade das edificações, na composição e distribuição das casas dos trabalhadores, no padrão estabelecido da moradia determinada pela estratificação social baseada na divisão social e territorial do 
trabalho. Todos esses elementos revelam a imposição do poder e o estabelecimento de uma divisão classista que busca se naturalizar a partir da paisagem.

O futuro desses lugares e suas respectivas paisagens encontram-se hoje em aberto, dentro do campo das possibilidades de desaparecerem com o tempo, pois consideramos improvável um retorno da economia sucroalcooleira. Assim, esse espaço pode receber novas funções, talvez podendo ser transformado em um espaço de memória, mesmo que em ruínas.

\section{BIBLIOGRAFIA}

Conceição, Raphael Neves da (2016). Leituras Geográficas da Paisagem da Baixada Campista. Dissertação (Mestrado em Geografia) - Programa de Pós-Graduação em Geografia da Universidade Federal Fluminense/UFF, Campos dos Goytacazes. Orientação de Elis de Araújo Miranda.

Cogrove, Denis (1978). "Place, landscape, and the dialectics of cultural geography". The Canadian Geographer, v. 22, n. 1, pp. 66-72.

Cosgrove, Denis (2012). “A geografia está em toda parte: cultura e simbolismo nas paisagens humanas'. In: Corrêa, Roberto Lobato; Rosendahl, Zeny (Orgs.). Geografia Cultural: uma antologia. Rio de Janeiro: EDUERJ, pp. 219-237.

Gantos, Marcelo Carlos; Quésia, Francisco de Souza (2006). "De usinas e usineiros: um ensaio sobre a decadência de uma cultura (Campos dos Goytacazes, 1930-2000)". In: Encontro Regional se História - O Historiador e seu Tempo, 18, 2006, São Paulo. Anais. São Paulo: Associação Nacional de História, Universidade Estadual de São Paulo "Júlio de Mesquita Filho"/Campus Assis. IBGE (1975). Coleção de Monografias n. 510: São Fidélis. Rio de Janeiro: IBGE. 3. Edição.

Lamego, Alberto Ribeiro (2007 [1946]). O Homem e o Brejo. Rio de Janeiro: Rio de Janeiro: IBGE.

Piquet, Rosélia (2003). "Da cana ao petróleo: uma região em mudança”. In: Piquet, Rosélia (Org.). Petróleo, royalties e região. Rio de Janeiro: Garamond, pp. 219-238.

Santos, Milton (1996). A Natureza do Espaço: Técnica e Tempo, Razão e Emoção. São Paulo: Editora da Universidade de São Paulo.

Santos, Milton (2014a). Espaço e Método. 5. ed., 2. reimp. São Paulo: EdUSP.

Santos, Milton (2014b). Da Totalidade ao Lugar. 1. ed., 3. reimp. São Paulo: EdUSP.

Silva, Rodrigo Pereira Pinheiro da (2019). A Usina Pureza de Açúcar e Álcool de São Fidélis-RJ: a resistência do passado na era do petróleo. Trabalho de Conclusão de Curso (Graduação em Geografia) - Universidade Federal Fluminense/UFF, Campos dos Goytacazes. Orientação: Elis de Araújo Miranda.

Smiderle, Dilcéia de Araújo Vieira (2010). 0 multiforme desafio do setor Sucroalcooleiro de Campos dos Goytacazes (RJ). Campos dos Goytacazes: Fundação Cultual Jonalista Oswaldo Lime. 


\section{RESUMOS}

A paisagem da Região Norte Fluminense é marcada pelos processos históricos vinculados à produção sucroalcooleira. Esse setor produtivo teve seu auge durante o século XIX e as duas primeiras décadas do século XX. A partir de então este sistema produtivo entrou em declínio, culminando no encerramento das atividades em quase todo conjunto de usinas. A Usina Pureza localizada no município de São Fidélis-RJ teve relevância no contexto regional, sendo uma das mais tradicionais indústrias de seu município, se destacando regionalmente. Esta usina encontrase fora de operação desde 2009 em decorrência de múltiplas dificuldades causadas pela desestruturação do sistema regional sucroalcooleiro. Este trabalho busca fazer uma leitura da paisagem da usina e das áreas ao seu entorno com o objetivo de identificar as transformações ocorridas após uma década de inatividade da indústria e as condições materiais de suas estruturas e compreender os aspectos simbólicos inerentes à composição dessas paisagens, amparado pela perspectiva crítica da Nova Geografia Cultural.

The landscape of the Northern Rio de Janeiro State is marked by historical processes linked to sugar-alcohol production. This productive sector had its peak during the 19th and the first two decades of the 20th century. From then on, this productive system went into decline, culminating in the closure of activities in almost all mills. The Pureza Plant, located in the municipality of São Fidélis-RJ, was relevant to the regional context, being one of the most traditional industries of its municipality and with regional outreach. This plant has been out of operation since 2009 on account of multiple difficulties caused by the destructuring of the regional sugar-alcohol system. This work aims to read the mill landscape and its surrounding areas in order to identify the transformations that occurred after a decade of this industrial inactivity, as well as the material conditions of its structures, seeking to also understand the symbolic aspects inherent in the composition of these landscapes, supported by the critical perspective of the New Cultural Geography.

Le paysage de la région de Nord d'État de Río de Janeiro est marqué par des processus historiques liés à la production de sucre-alcool. Ce secteur productif a connu son apogée au cours du XIXe siècle et des deux premières décennies du XXe siècle. Dès lors, ce système productif s'est dégradé et a abouti à la fermeture d'activités dans la quasi-totalité des usines. L'usine de Pureza, située dans la municipalité de São Fidélis-RJ, était pertinente dans le contexte au nord d'état, comme une des industries les plus traditionnelles de sa municipalité et au niveau régional. Cette usine est hors service depuis 2009 en raison des multiples difficultés causées par la déstructuration du système régional de production d'alcool à partir du sucre. Cet ouvrage cherche à faire une lecture du paysage du moulin et de ses environs afin d'identifier les transformations qui se sont produites après une décennie d'inactivité de l'industrie et les conditions matérielles de ses structures. Cette étude vise à comprendre aussi les aspects symboliques inhérents à la composition de ces paysages, soutenus par la perspective critique de la nouvelle géographie culturelle.

El paisaje de la Región Norte del Estado de Río de Janeiro está marcado por procesos históricos vinculados a la producción sucroalcoholera. Este sector productivo tuvo su apogeo durante el siglo XIX y las dos primeras décadas del siglo XX. A partir de entonces, este sistema productivo entró en declive, culminando con el cierre de actividades en casi todos los molinos. La Planta Pureza, ubicada en el municipio de São Fidélis-RJ, tuvo relevancia en el contexto norte del Estado, siendo una de las industrias más tradicionales de su municipio y de destaque regional. Esta planta ha estado fuera de operación desde 2009 debido a las múltiples dificultades causadas por la desestructuración del sistema regional sucroalcoholero. Este trabajo busca hacer una lectura del paisaje del molino y de las zonas circundantes para identificar las transformaciones que se 
produjeron tras una década de inactividad de la industria, así como las condiciones materiales de sus estructuras, buscando entender también los aspectos simbólicos inherentes a la composición de estos paisajes, apoyados en la perspectiva crítica de la Nueva Geografía Cultural.

\section{ÍNDICE}

Keywords: landscape, northern Rio de Janeiro state, sugar-alcohol economy, São Fidélis, ruins Palabras claves: Paisaje, región norte del estado de Río de Janeiro, economía sucroalcoholera, São Fidélis, ruinas

Índice cronológico: século XIX; século XX

Índice geográfico: Norte Fluminense

Palavras-chave: paisagem, região norte fluminense, economia sucroalcooleira, São Fidélis, ruínas

Mots-clés: paysage, région nord d'état de Río de Janeiro, economie du sucre et de l'alcool, São Fidélis, ruines

\section{AUTORES}

\section{RODRIGO PEREIRA PINHEIRO DA SILVA}

Geógrafo. Mestrando do Programa de Pós-Graduação em Desenvolvimento Regional, Ambiente e Políticas Públicas (PPGDAP) da Universidade Federal Fluminense (UFF).

E-mail: rodrigo_pereira@id.uff.br

\section{ELIS DE ARAÚJO MIRANDA}

Geógrafa. Doutora em Planejamento Urbano e Regional. Professora Associada do Programa de Pós-Graduação em Desenvolvimento Regional, Ambiente e Políticas Públicas (PPGDAP) da Universidade Federal Fluminense (UFF).

E-mail: elismiranda@id.uff.br 